\title{
Distribution of missing women in outpatient clinics of a tertiary health care facility in India
}

\author{
Urvashi Khan', Anupam Kumar Singh ${ }^{2 *}$ \\ ${ }^{1}$ Post Graduate Resident, ${ }^{2}$ Assistant Professor, Dept. of General Medicine, Santosh Medical College and Hospital, Ghaziabad, Uttar \\ Pradesh, India
}

*Corresponding Author: Anupam Kumar Singh

Email: draksinghmedicine@gmail.com

\begin{abstract}
Introduction: There is a Paucity of Studies exploring Gender disparity in health care access factors affecting it in Developing countries. Aims and objectives: Analysis of gender disparity in access to healthcare and its relationship with the patient's age and distance from the Hospital.

Materials and Methods: A retrospective observational cross sectional study based on outpatient data from a Private Medical College in Ghaziabad. Cross tabulation were done for Sex and age class(young, middle, older) and Estimates from hierarchical logistic regression were used to compute sex ratios (male/female) of patient visits as a function of age and distance (in kilometers) from the hospital and age.

Results: A total of 1 lakh 86 patients visited Santosh Hospital Outpatient clinics 2,11,183 times in departments of Medicine, Surgery, Pulmonary Medicine, Paediatrics, Psychiatry, Orthopaedics and Dermatology from July 2018 to July 2019. Out of these 1 lakh 86 patients - 51022 were Males and 49844 were females (Sex ratio of 1.02). Sex ratio had a parabolic (U curve) relationship with Age implying that Sex ratio worsened at extreme age. The Sex ratio in age groups 0-18,19-30,31-45,46-60 and >60 are 1.21,1.06,0.91,1.01 and 1.14 respectively. On adjusting for department in multivariable logistic regression, distance from hospital (available in 820 patients) was significantly associated with probability of a male outpatient visit. Odds Ratio $(1.23,95 \%$ CI 1.02-1.48, P value $=0.046)$

Conclusion: Gender disparity was observed in access to healthcare, which was worse at extremes of age (younger and older age groups) and at higher distance from Hospital.
\end{abstract}

Keywords: Sex Ratio, Gender disparity, Health access, Primary health care, Demographic profile.

\section{Introduction}

Gender inequality permeates different realms of life. The numbers- sex ratios, gender development indices, abysmally tell us a story of inequality and negligence leading to higher mortality among females. ${ }^{1}$ It leads to the unavoidable problems of missing women population in healthcare. It's a bigger funnel but sadly a steep fall.

Studies on gender disparity have only now begun to gain momentum but a research of gender disparity in access to healthcare remains relatively unexplored both in India and worldwide. Previous studies have largely focused on the raised mortality of female patients as compared to male patients, to explain the issues accompanied with missing females. $^{2-7}$

Recent prior research has focussed on gender disparity in the use of outpatient health care services. However there is conflicting data among in western countries like USA, South Korea and Germany women rely on medical services more than men, ${ }^{8}$ while in Developing countries like Ghana and India, Male use is higher. ${ }^{2,8}$

A recent study exploring health care utilization in outpatient clinic at AIIMS Delhi showed that Male: Female Sex ratio is high (1.69) and further worsens at extremes of age (young children and elderly) and with increasing distance (Farther states have worse ratio). However, AIIMS Delhi is a tertiary referral centre and it is important to validate the findings in community hospital with more granular estimates of effect on sex ratio with increasing distance.
We hypothesized women's deprived access to healthcare is related to patient's distance from health care facility and age. Thus the aimed to analyse sex ratio in outpatient clinics at various department over course of one year and determined effect of age and distance on health care access and examine the gender disparity. Health cares can make important contributions to gender equality by addressing gender in a variety of ways.

\section{Materials and Methods}

An observational cross sectional study was carried out in Santosh Medical College, Ghaziabad, from August 2018 to July 2019. For this study, used existing data on 2,11,183 outpatient visits to Santosh Medical College and Hospitals, Ghaziabad for the year August 2018 to July 2019 across outpatient departments (Medicine, Surgery, Pulmonary Medicine, Paediatrics, Psychiatry, Orthopaedics and Dermatology). The data was collected from the Medical Records Department at Santosh Hospital. For each patient gender, age, residence, and hospital outpatient department visited were noted. We stratified patients into five age groups: 0-18 years, 19-30 years, 31-44 years, 45 -59 years, and 60 years or over. Most patients belonged to Uttar Pradesh. The number of unique patients and their repeated visits was noted using their unique ID. Longitude and latitude of 1000 locations were batch geocoded using google map API and distance between the places and Santosh Hospital calculated using geosphere package in R 3.5.

Missing female patients for each department and age group subclass computed as the difference in the actual 
number of female patients who came from each state and the number of female patients that should have visited the hospital (if male and female patients had come in the same proportion as the sex ratio of the overall Uttar Pradesh population from the 2011 census).

\section{Statistical analysis}

We performed mixed effects logistic regression, with the dependent variable being likelihood of a male patient visit and clusters at the level of id (accounting for repeated visits by same individuals). The main explanatory variables are age group(continuous variable), department (indicator variable with 6 classes- Medicine, Surgery, Pulmonary Medicine, Paediatrics, Psychiatry, Orthopaedics and Dermatology) and Distance in kilometers(for geocoded samples). R package lme4 was used for the above analysis. Odds ratio Estimates were also calculated separately for age classes and Departments. Lowess plots indicating non-linear relationship between Age and Sex ratio were made to illustrate relation between age and sex, both overall and for each department.

\section{Results}

A total of 1 lakh 86 patients visited Santosh Hospital Outpatient clinics 2,11,183 times in departments of Medicine, Surgery, Pulmonary Medicine, Paediatrics, Psychiatry, Orthopaedics and Dermatology from July 2018 to July 2019. Thus, one patient visited Santosh hospital an average 2.09 times. 1,07,667 visits out of these were made by Male patients and 1003516 visits were made by Female patients implying an outpatient sex ratio of 1.04 in our population. Thus the Sex ratio was significantly better than Sex ratio of India $(1000 / 940=1.06)$ and Sex ratio of Uttar Pradesh $(1000 / 912=1.09)$ as per results of Census 2011. Out of these 1 lakh 86 patients - 51022 were Males and 49844 were females (Sex ratio of 1.02). Significantly higher percentage of Females had Follow up visits than Males $[49844 / 1003516(48.1 \%)$ vs 51022/107667 (47.3\%), Difference $=0.8 \%, 95 \%$ Confidence Interval $=0.3 \%$ to $1.1 \%$, $\mathrm{p}$ value $<0.001)$.

\section{Variation of sex ratio with age}

Sex ratio had a parabolic relationship (U Shaped) with Age implying that sex ratio worsened at extreme age. (Fig. 1)

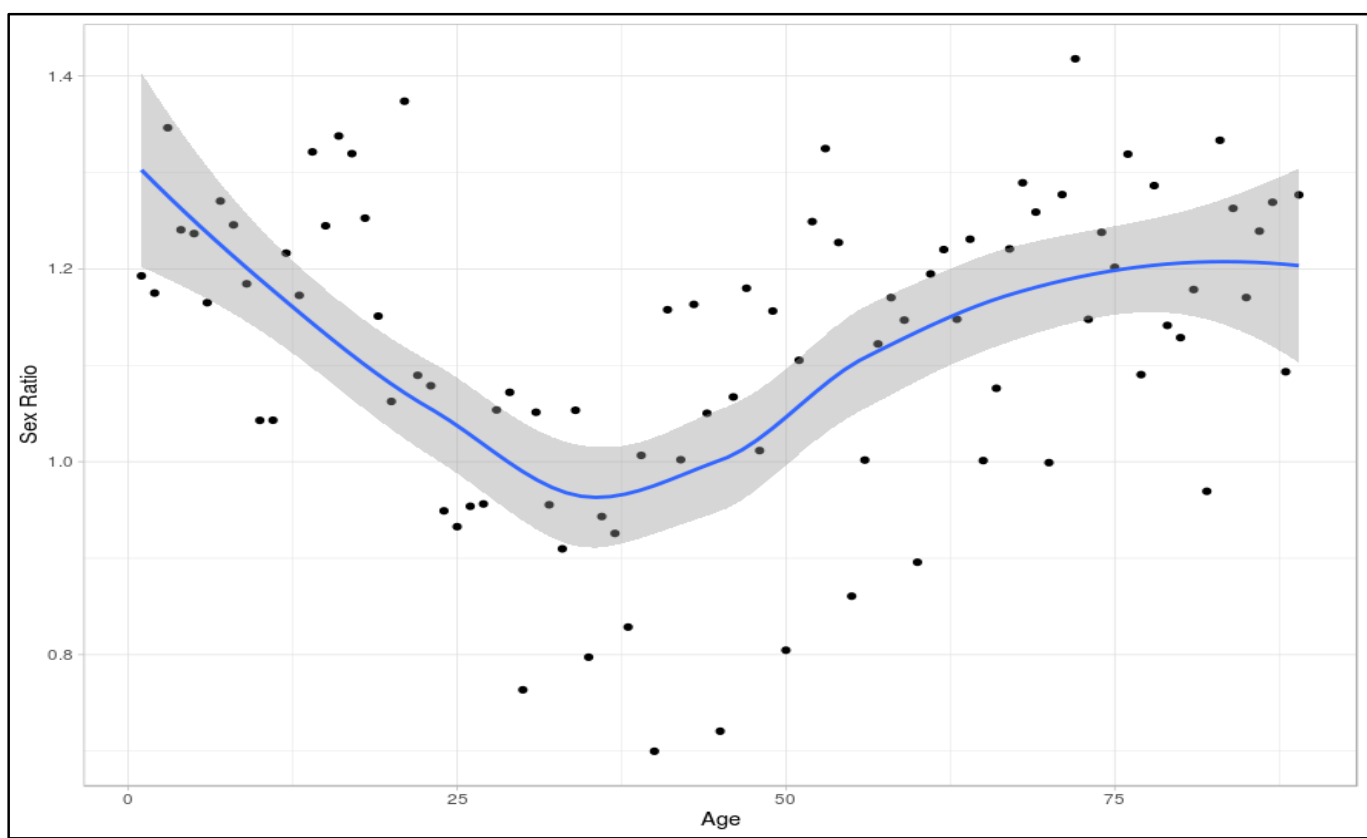

Fig. 1: A scatter plot of Sex ratio with Age -Points have been jittered for clarity, loess smoother line has been used to demonstrate variation at extremes of age

The sex ratio in age groups $0-18,19-30,31-45,46-60$ and $>60$ are $1.21,1.06,0.91,1.01$ and 1.14 respectively.

Table 1: Overall sex ratio distribution across various age categories

\begin{tabular}{|l|c|c|c|c|}
\hline Age Category & Age Group & Female & Male & Sex Ratio \\
\hline Young & $0-18$ & 11853 & 14382 & 1.21 \\
\hline Young & $19-30$ & 22213 & 23537 & 1.06 \\
\hline Middle & $31-45$ & 27902 & 25252 & 0.91 \\
\hline Middle & $46-60$ & 21925 & 22077 & 1.01 \\
\hline Old & $>60$ & 19623 & 22419 & 1.14 \\
\hline
\end{tabular}




\section{Variation of sex ratio with departments}

Table 2: Sex ratio in departments across various age categories

\begin{tabular}{|c|c|c|c|}
\hline Age Category & Female & Male & Sex Ratio \\
\hline \multicolumn{4}{|c|}{ Dermatology } \\
\hline Young & 7316 & 7932 & 1.08 \\
\hline Middle & 7687 & 6621 & 0.86 \\
\hline Old & 1023 & 1350 & 1.32 \\
\hline Overall & 16026 & 15903 & 0.99 \\
\hline \multicolumn{4}{|c|}{ Medicine } \\
\hline Young & 4848 & 4522 & 0.93 \\
\hline Middle & 10953 & 8782 & 0.8 \\
\hline Old & 5093 & 5756 & 1.13 \\
\hline Overall & 20894 & 19060 & 0.91 \\
\hline \multicolumn{4}{|c|}{ Orthopedics } \\
\hline Young & 3463 & 3874 & 1.12 \\
\hline Middle & 10007 & 8538 & 0.85 \\
\hline Old & 2603 & 2537 & 0.97 \\
\hline Overall & 16073 & 14949 & 0.93 \\
\hline \multicolumn{4}{|c|}{ Paediatrics } \\
\hline Overall & 9844 & 11788 & 1.2 \\
\hline \multicolumn{4}{|c|}{ Psychiatry } \\
\hline Young & 2288 & 2586 & 1.13 \\
\hline Middle & 5781 & 5825 & 1.01 \\
\hline Old & 1700 & 1855 & 1.09 \\
\hline Overall & 9769 & 10266 & 1.05 \\
\hline \multicolumn{4}{|c|}{ Pulmonary Medicine } \\
\hline Young & 3666 & 3872 & 1.06 \\
\hline Middle & 9644 & 10786 & 1.12 \\
\hline Old & 5504 & 6540 & 1.19 \\
\hline Overall & 18814 & 21198 & 1.13 \\
\hline \multicolumn{4}{|c|}{ Surgery } \\
\hline Young & 2641 & 3345 & 1.27 \\
\hline Middle & 5755 & 6777 & 1.18 \\
\hline Old & 3700 & 4381 & 1.18 \\
\hline Overall & 12096 & 14503 & 1.2 \\
\hline
\end{tabular}

We see among the branches: Surgery has highest Male: Female sex ratio followed closely by Paediatrics, Pulmonary Medicine and Psychiatry. Dermatology has sex ratio close to one while orthopedics and General Medicine have higher number of outpatient female to male ratio. Even within Department the Male: Female ratio is higher in young and old compared to Middle. (Except Paediatrics which has young patients only and surgery where high Male: Female ratio is preserved across age groups) (Fig. 2) 


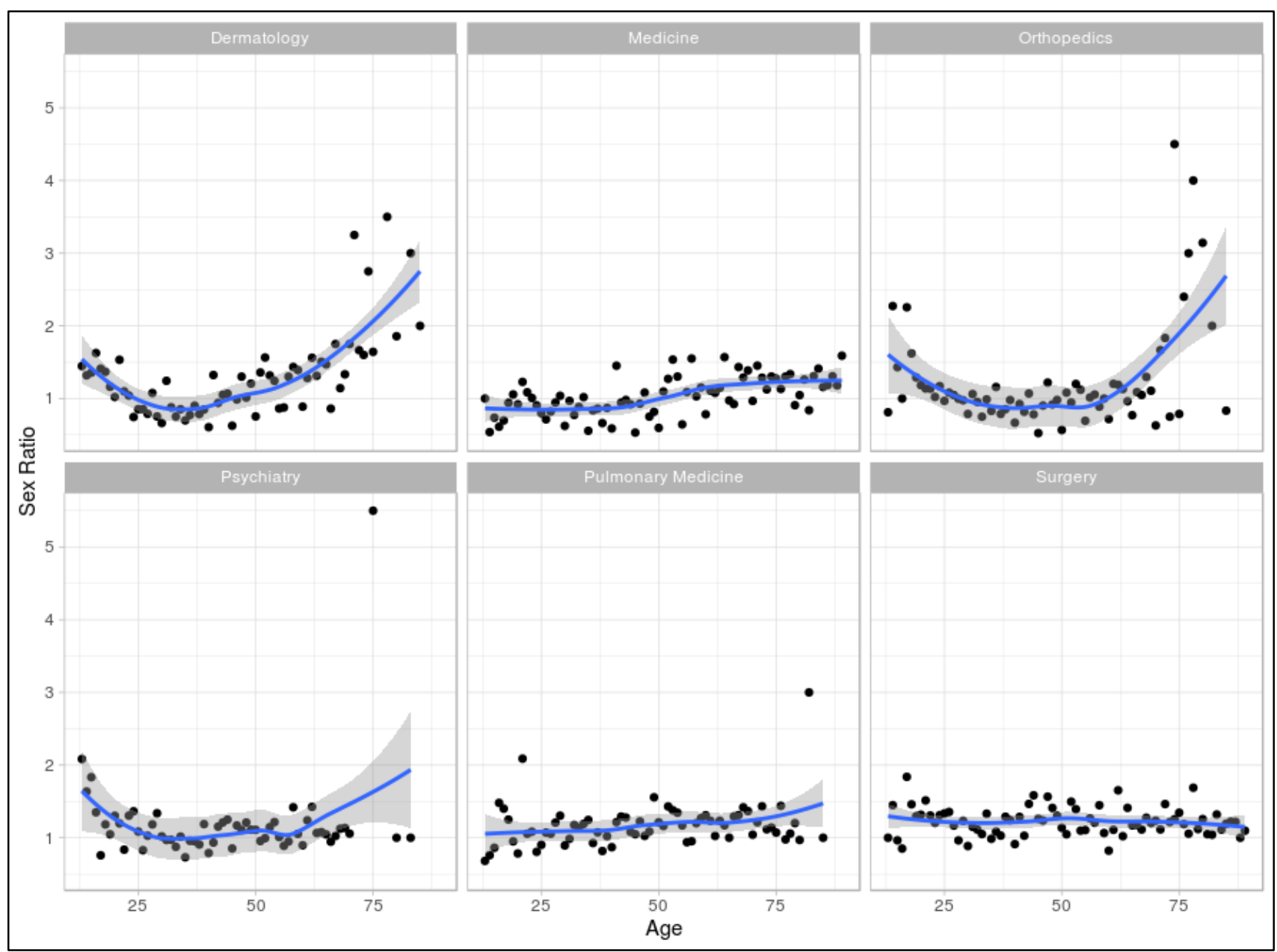

Fig. 2: A panel scatter plot of sex ratio with age -points have been jittered for clarity, loess smoother line has been used to demonstrate variation at extremes of age. The panels represent various departments of Hospital

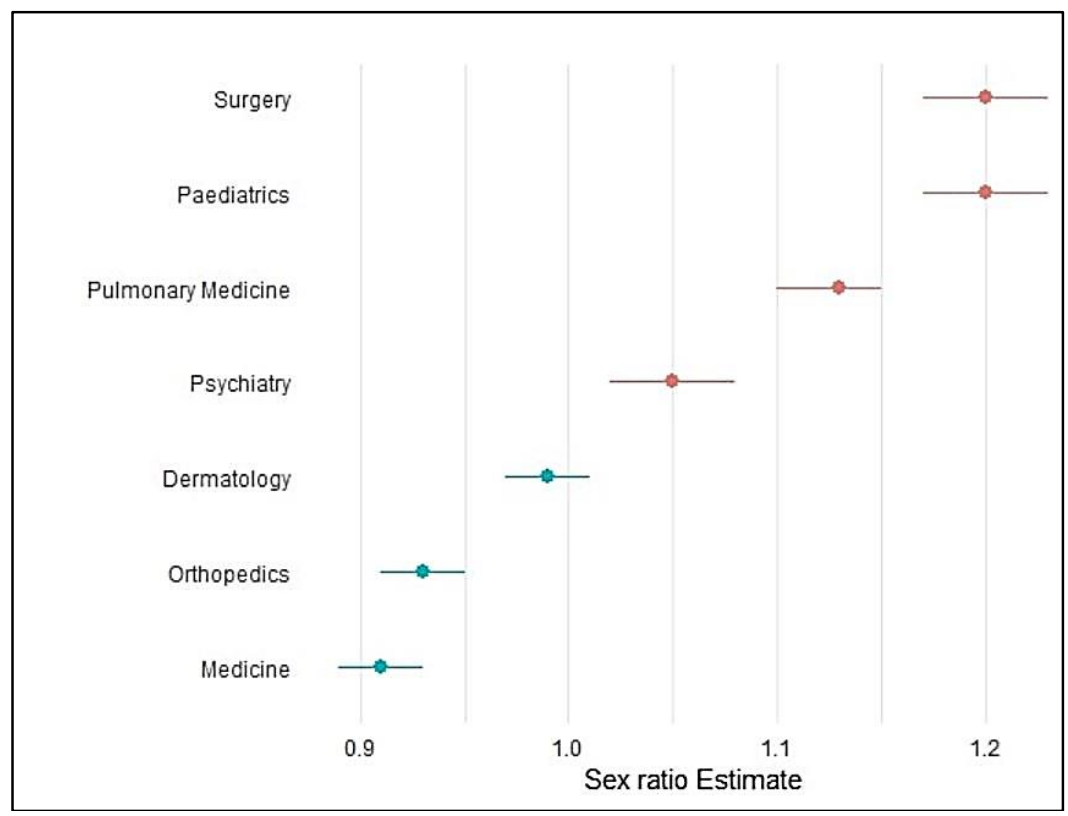

Fig. 3. Forest plot of confidence interval of sex ratio in outpatient clinic across department. 


\section{Missing Female Patients}

Table 3: Number of missing female patients in departments categorised by age group. A negative sign in absolute numbers and percentage indicates lower Female/Male ratio than expected in the particular age group as per 2011 census statistics

\begin{tabular}{|c|c|c|c|c|c|}
\hline Age & Male Visits & Female Visits & $\begin{array}{c}\text { Potential Female } \\
\text { visits }\end{array}$ & Missing Females & $\begin{array}{c}\text { Missing } \\
\text { Percentage }\end{array}$ \\
\hline \multicolumn{6}{|c|}{ Dermatology } \\
\hline $0-18$ & 1515 & 1054 & 1348 & -294 & -27.89 \\
\hline $19-30$ & 6417 & 6262 & 5916 & 346 & 5.53 \\
\hline $31-45$ & 4043 & 5075 & 3728 & 1347 & 26.54 \\
\hline $46-60$ & 2578 & 2612 & 2377 & 235 & 9 \\
\hline$>60$ & 1350 & 1023 & 1243 & -220 & -21.51 \\
\hline \multicolumn{6}{|c|}{ Medicine } \\
\hline $0-18$ & 142 & 210 & 126 & 84 & 40 \\
\hline $19-30$ & 4380 & 4638 & 4038 & 600 & 12.94 \\
\hline $31-45$ & 4603 & 6010 & 4244 & 1766 & 29.38 \\
\hline $46-60$ & 4179 & 4943 & 3853 & 1090 & 22.05 \\
\hline$>60$ & 5756 & 5093 & 5301 & -208 & -4.08 \\
\hline \multicolumn{6}{|c|}{ Orthopedics } \\
\hline $0-18$ & 336 & 228 & 299 & -71 & -31.14 \\
\hline $19-30$ & 3538 & 3235 & 3262 & -27 & -0.83 \\
\hline $31-45$ & 4564 & 5309 & 4208 & 1101 & 20.74 \\
\hline $46-60$ & 3974 & 4698 & 3664 & 1034 & 22.01 \\
\hline$>60$ & 2537 & 2603 & 2337 & 266 & 10.22 \\
\hline \multicolumn{6}{|c|}{ Paediatrics } \\
\hline $0-18$ & 11788 & 9844 & 10491 & -647 & -6.57 \\
\hline \multicolumn{6}{|c|}{ Pulmonary Medicine } \\
\hline $0-18$ & 290 & 272 & 258 & 14 & 5.15 \\
\hline $19-30$ & 3582 & 3394 & 3303 & 91 & 2.68 \\
\hline $31-45$ & 5416 & 5112 & 4994 & 118 & 2.31 \\
\hline $46-60$ & 5370 & 4532 & 4951 & -419 & -9.25 \\
\hline$>60$ & 6540 & 5504 & 6023 & -519 & -9.43 \\
\hline \multicolumn{6}{|c|}{ Surgery } \\
\hline $0-18$ & 197 & 161 & 175 & -14 & -8.7 \\
\hline $19-30$ & 3148 & 2480 & 2902 & -422 & -17.02 \\
\hline $31-45$ & 3517 & 3171 & 3243 & -72 & -2.27 \\
\hline $46-60$ & 3260 & 2584 & 3006 & -422 & -16.33 \\
\hline$>60$ & 4381 & 3700 & 4035 & -335 & -9.05 \\
\hline
\end{tabular}

The number of missing female patient visits based on sex ratios available for UP (0-18 yrs: 891, 19-60:922, > 60: 921) from the population Census (2011) is presented in Table 3.

For a given age group category number of Missing Female visits were determined in two steps

Potential Female visits $=$ Total Male visits in that age group / Sex ratio (Male: Female) in that age group.

Missing Female visits $=$ Potential Female Visits - Total female Visits in that age group.

As an example in Surgery, there were a total of 2480 female and 3148 male patient visits to the hospital in the age group 19-30 years. If the female patients had visited in the same proportion as the male to female ratio of the census, then the total number of female patients to Surgery (Potential Female visits) would have been 2902. Therefore, the number of missing female patient visits in department of surgery for the age group 19-30 years is 422 (denoted with a negative sign in table) which is approximately $17 \%$ of the total female visits to Surgery for that particular age group. 


\section{Logistic regression}

Table 4: Adjusted odds ratio with $95 \%$ confidence interval estimates for age group and department adjusted for distance based on logistic regression. Standard errors were clustered at individual level

\begin{tabular}{|l|c|c|c|c|}
\hline Variable & Odds Ratio & Lower CI & Upper CI & P value \\
\hline \multicolumn{5}{|c|}{ Age Class } \\
\hline $0-18$ & 1.21 & 1.18 & 1.24 & $<0.001$ \\
\hline $19-30$ & 1.06 & 1.04 & 1.08 & $<0.001$ \\
\hline $31-45$ & 0.9 & 0.89 & 0.92 & $<0.001$ \\
\hline $46-60$ & 1.01 & 0.99 & 1.03 & 0.47 \\
\hline$>60$ & 1.14 & 1.12 & 1.16 & $<0.001$ \\
\hline \multicolumn{5}{|c|}{ Department } \\
\hline Medicine & 0.91 & 0.89 & 0.93 & $<0.001$ \\
\hline Surgery & 1.2 & 1.17 & 1.23 & $<0.001$ \\
\hline Pulmonary Medicine & 1.13 & 1.1 & 1.15 & $<0.001$ \\
\hline Psychiatry & 1.05 & 1.02 & 1.08 & $<0.001$ \\
\hline Orthopedics & 0.93 & 0.91 & 0.95 & $<0.001$ \\
\hline Paediatrics & 1.2 & 1.17 & 1.23 & $<0.001$ \\
\hline Dermatology & 0.99 & 0.97 & 1.01 & 0.49 \\
\hline
\end{tabular}

Logistic regression was used to calculate odds ratio for each department and age group separately while adjusting for distance. Estimates are presented in Table 3.

\section{Variation of sex ratio with distance}

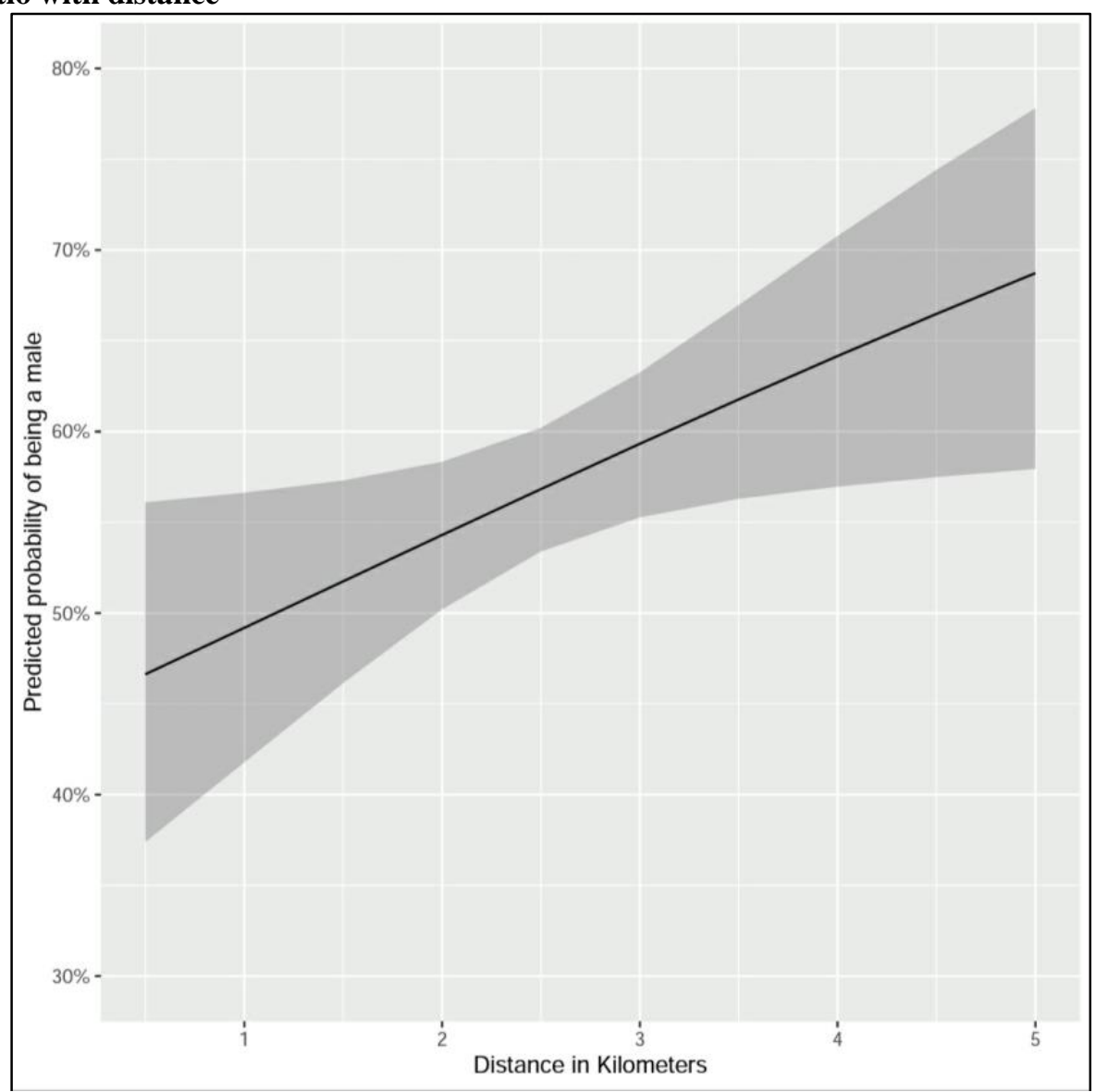

Fig. 4: Variation in predicted probability of a male outpatient visit with distance from hospital in kilometers. The shaded area represents confidence interval of estimate 
On adjusting for department in multivariable logistic regression, distance from Hospital (available in 820 patients) was significantly associated with Probability of a male outpatient visit. Odds Ratio $(1.23$, 95\% CI 1.019$1.477, \mathrm{P}$ value $=0.046)$.

It can be interpreted, as - At mean Distance from Hospital (2.5 Kilometers), every unit $(1 \mathrm{~km})$ increase in distance will increase probability of male outpatient visit by $5 \%$.

\section{Variation of Sex ratio with weekdays}

There is no significant trend in variation of Sex ratio in outpatient clinic on week days.

Table 5

\begin{tabular}{|l|c|c|c|}
\hline Weekday & Sex Ratio & LCI & HCI \\
\hline Monday & 1.012 & 0.991 & 1.033 \\
\hline Thursday & 1.012 & 0.99 & 1.035 \\
\hline Tuesday & 1.033 & 1.011 & 1.055 \\
\hline Friday & 1.054 & 1.031 & 1.078 \\
\hline Saturday & 1.058 & 1.04 & 1.078 \\
\hline Wednesday & 1.067 & 1.044 & 1.092 \\
\hline Sunday & 1.138 & 0.97 & 1.335 \\
\hline
\end{tabular}

\section{Discussion}

We found a significant $\mathrm{U}$ curve in relationship of male to female sex ratio with Age.

The sex ratio worsened with increasing distance from Hospital on adjusting for department and Age. There was no significant weekday wise variation in sex ratio.

The present findings agree with a previous India based study by Kapoor et $\mathrm{al}^{2}$ at AIIMS Delhi, where they found a higher male: female sex ratio in health care utilisation at outpatient level in 2016. However, sex ratio at our Hospital (1.02) was considerably better than that at AIIMS (1.69) and sex ratio from Indian and UP census (1.06 and 1.09 respectively).

It may be explained by tertiary nature of AIIMS, where a significant proportion of patients are from referral population, other states and travel large distances to reach Hospital rather than the present Hospital, which is a community Hospital and caters to most of the population from Ghaziabad only (Mean Distance $2.5 \mathrm{~km}$ ).

However, the present findings differ from study by Vaidya et $\mathrm{al}^{10}$ and Noh et $\mathrm{al}^{11}$ which were carried out in South Korea and USA respectively and Females had significantly higher health care utilization than male. This can be explained by higher socioeconomic strata of health care seeking population in USA based study by Vaidya et $\mathrm{a}^{10}$ and inclusion of Obstetrics and Gynaecology department cases in study by Noh et al. ${ }^{11}$

Similar findings have been observed in Ghana by Daniel et $\mathrm{al}^{12}$ where they found that despite greater desire for medical service use among women, actual use is lesser, suggesting that limiting factors like distance, insufficient time, as well as social and educational status.
However, it was found similar Parabolic Curve (worsened sex ratio at extremes of age) similar to study by Kapoor et $\mathrm{al}^{2}$ (across most Departments and overall as well). Possible causes might be lack of autonomy in health care access as Population at extremes of age are not in work productive category and don't have financial independence.

We also found that with each increasing kilometer male female skews further (Five percent increased probability of male visit). This was indirectly inferred in Study by Kapoor et $\mathrm{al}^{2}$ (1.41 for Delhi, 1.70 for Haryana, 1.98 for Uttar Pradesh and 2.37 for Bihar: indicating sex ratio worsens for farthest state). It can be possibly explained as females have more difficulty in traveling for health care access than males.

All departments had worsened sex ratio except department of surgery - can be explained by male predominant diseases (hernia, hydrocele) in surgery outpatient clinics. Department of Paediatrics had younger population only and hence male: female sex ratio was consistently higher.

Strengths of this Study are: Use of a Community Hospital Database, Mapping sex ratio across various Departments and studying its relationship with age and distance.

One potential limitation of this study is that skew in sex ratio can be due to inherent age and gender distribution of diseases rather than problem of access, but considering the skew is present across Departments it is more likely to be population related.

\section{Conclusion}

Present study validates the existence of gender disparity in outpatient health care access that worsens at extremes of age and with distance in Indian Scenario.

\section{Source of funding}

None.

\section{Conflicts of interest}

None.

\section{References}

1. Verbrugge LM. A health profile of older women with comparisons to older men. Res Aging 1984;6:291-322.

2. Kapoor M, Agrawal D, Ravi S, Roy A, Subramanian SV, Guleria R. Missing female patients: an observational analysis of sex ratio among outpatients in a referral tertiary care public hospital in India. BMJ Open 2019;9(8):e026850.

3. Amartya S. Missing women-revisited. BMJ 2003;327:129798.

4. Bongaarts J, Guilmoto C. How many more missing women? Lancet 2015;386:427-34.

5. Anderson S, Ray D. Missing women: age and disease. Rev Econ Stud 2010;77:1262-300.

6. Anderson S, Ray D. The age distribution of missing women in India. Econ Pol Wkly 2012:12:87-95.

7. Balan S, Mahalingam R. Are we losing the war on missing girls?. Lancet Glob Health 2014;2:e22.

8. Yu MK, Lyles CR, Bent-Shaw LA, Young BA. Sex disparities in diabetes process of care measures and self-care in high-risk patients. J Diabet Res 2013;3:1-9 
9. Oertelt-Prigione S, Regitz-Zagrosek V, editors. Sex and gender aspects in clinical medicine. Springer Science \& Business Media; 2011.

10. Vaidya V, Partha G, Karmakar M. Gender differences in utilization of preventive care services in the United States. $J$ Womens Health 2012;21:140-5.

11. Noh JW, Kim KB, Park H, Kwon YD. Gender differences in outpatient utilization: a pooled analysis of data from the Korea Health Panel. J Women's Health. 2017;26(2):178-85.

12. Buor D. Gender and the utilisation of health services in the Ashanti Region, Ghana. Health Policy 2004;69:375-88. 